\title{
Looking women seriously: what makes differences for women participation in community forestry?
}

\author{
P. K. C. Bhandari ${ }^{1 *}$, P. Bhusal ${ }^{1}$, B. B. Khanal Chhetri ${ }^{1}$ and C. P. Upadhyaya ${ }^{1}$
}

\begin{abstract}
Women participation has been in discussion for long in community forestry in Nepal - a successful programme in participatory forest governance. Despite having ample of policy instruments to address the women concern in community forestry decision making activities several pragmatic issues have been encountered. This paper examines on the women participation in different community forestry decision making activities and identifies the factors influencing participation in such activities. The evidences were generated from five community forest user groups in Kaski district. The analysis was based on the household surveys that included the random sample of 213 respondents (107 females and 106 males). Similarly, regular triangulation and verification of the data were made through series of interviews, discussions and observations followed by the analysis of CF documents. Three ordered logit regression models were deployed to examine the determinants of women participation in decision making in forest management, resource utilization and participatory activities. The analysis showed lower participation of women in community forest decision making activities. Gender had the significant association with the participation in all decision making activities. The men with higher education, who are the member of executive committee and have access to community forestry fund, had participated significantly more than women in community forestry decision making activities. Low participation of women was associated with lower representation in user group committee, social and traditional beliefs and preoccupied assumption that women cannot lead which may result in unfair implication of community forestry.
\end{abstract}

Key words: Community forestry, decision making, gender, participation

$\mathrm{C}$ ommunity forestry (CF) has been cited as the successful model to ensure the participation of local communities for better forest management. Currently, about $35 \%$ of Nepal's population is involved in community forestry programme through 22,266 Community Forest User Groups (CFUGs), in which women led CFUGs are $6 \%$ and CF covers $33 \%$ of the total forest area in Nepal (DoF, 2018). CF is considered as the global innovation in the field of participatory environmental governance (Kumar, 2002). The innovations of community forestry in operational activities, legislative development and evolving practices have helped in enhancing the access to forest products, improving livelihood opportunities for forest dependent people, strengthening local institutional capacity, and improving ecological conditions of forests
(Ojha and Pokharel, 2005; Pokharel et al., 2007). However as its success has been grown up with the participation of communities in forest management the women participation has been always low in decision making (Chhetri et al., 2013; Wagle et al., 2017). Usually women have been involving in the collection of fuel wood, fodder, medicinal plants and other non-timber forest products (Shiva, 1989; Agarwal, 2010). The gender relation has the direct effect on forest use and management as women are the key forest users with major stakes in forest governance.

Gender biases persist in forestry research and practice; as a result, there has been reduced scientific rigor and inequitable, less efficient policies, programmes, and interventions (Elias et al., 2017). The lack of a recognized role

1 Institute of Forestry, Pokhara Campus, Pokhara, Nepal. * E-mail: puspa_kcbhandari@yahoo.co.uk 
of women in public forums, limited access to information and norms of silence results in the exclusion of women from decision making (Agarwal, 2002). The gender and other factors of social differentiation like age, socio-economic status, social constructs and the gender division has critical role in defining who can participate in decision making, in forest management and obtaining the associated benefits (Howard and Nabanoga 2007; Elias et al., 2017). There have been several discussions at different sphere to enhance the participation of women in community forestry. Since the emergence of community forestry in Nepal, there has been gradual progress towards recognizing gender equity through laws, policies and strategies. The community forestry guideline 2015, the Gender Equality and Social Inclusion strategy and the Forest Sector Gender and Social Inclusion strategy (MFSC, 2012) have emphasized and legally ensured women participation in decision making. However the participation of women remains low and many of the women who are in the Executive Committee (EC) are serving as a token representative without exercising the authority (Lama et al., 2017). Although the women participation in CFUGs EC is increasing it is still beyond the target (FAO and RECOFTC, 2015) and particularly in terms of decision making it is always debatable. The policy change has shown its minimal and slow effects however there needs to be intense and focused actions and programmes to sensitize, prepare, involve and learn women for better and effective application of policy in real ground.

The women's role is crucial in community forestry management in Nepal as it affects in the intensity of the cooperation in forest management. Though women participation in decision making activities have been recognised through several policies in 40 years of community forest development, still the issue of meaning participation has always been contested. Women participation is still costly and they have been bounded by several factors. Thus it needs to be explored more and need a lot of case studies for consolidated effects for long term outcome on forest management. In this context this paper has explored on the women participation in decision making activities in community forestry in the Mid Hill through collection of empirical data from five CFUGs and has tested the existing knowledge. Similarly the study will fulfil the knowledge gap particularly, on decision making activities that women participate or they are requested to participate. Equally, we have analysed the determinants of women participation in decision making process.

\section{Materials and methods}

\section{Study area}

The study was carried out in five CFUGs in Kaski District which lies in the middle mountain region of Nepal (Fig. 1). A total of 501 community forest areas have been transferred to local communities, which are managed by 46,390 households (HHs) in the district (DoF, 2018). Out of the total forest user committee members, $37 \%$ are women and five CFUGs are led by them. The data was collected during December 2015 to February 2016. The consultation was made with the staff of District Forest Office before selecting the study area. The selected five CFUGs (Table 1) were from almost all parts of the district. Other criteria for selection of CFUGs included representation of mixed castes, at least five years of CF establishment and the good size of the annual income (more than one million).

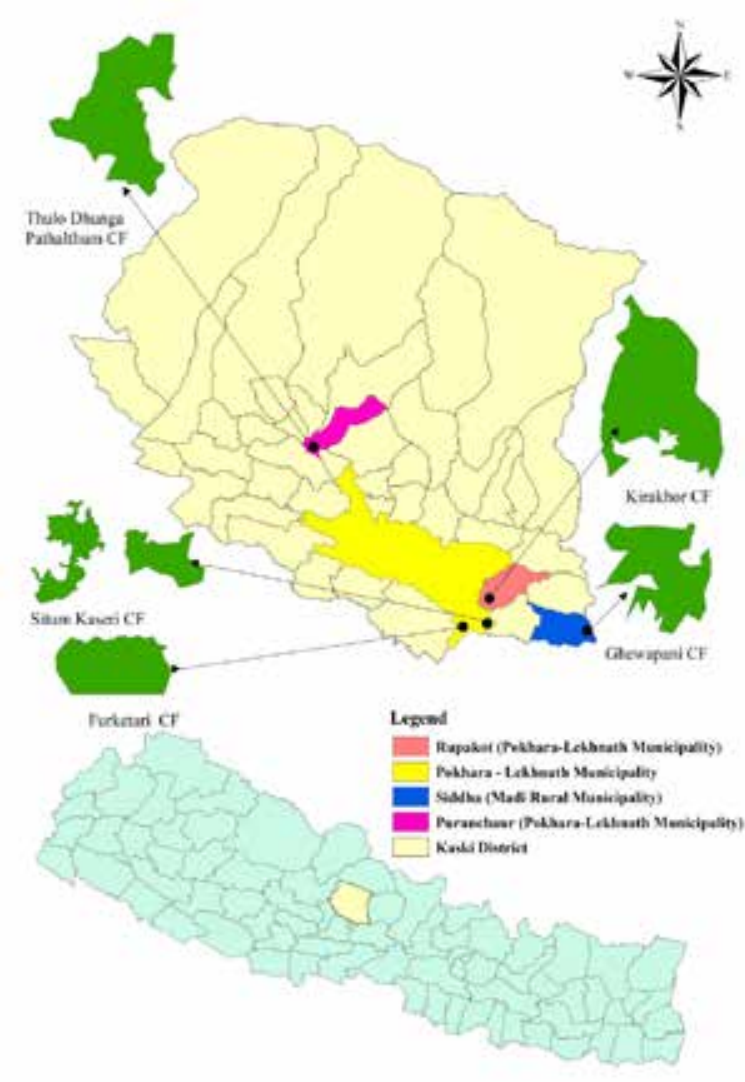

Fig. 1: Map showing study area 
Table 1: Summary data of study CFUGs

\begin{tabular}{|l|l|c|c|c|c|c|}
\hline SN & \multicolumn{1}{|c|}{ Name of CFUG/address } & $\begin{array}{c}\text { No of } \\
\text { HHs }\end{array}$ & $\begin{array}{c}\text { CF } \\
\text { area } \\
\text { (Ha) }\end{array}$ & $\begin{array}{c}\text { Sample } \\
\text { size (HHs) }\end{array}$ & \multicolumn{2}{|c|}{$\begin{array}{c}\text { Number of } \\
\text { respondents by gender }\end{array}$} \\
\cline { 5 - 7 } 1 & $\begin{array}{l}\text { Thulo Dhungapatalthum(Puranchur, } \\
\text { Wards 6,7,9) }\end{array}$ & 154 & 27.94 & 42 & 20 & 22 \\
\hline 2 & $\begin{array}{l}\text { Ghewapanikusunde (Siddha, Wards } \\
8,9)\end{array}$ & 252 & 106 & 50 & 25 & 25 \\
\hline 3 & $\begin{array}{l}\text { Situmkaseri (Lekhnath Municipality, } \\
\text { Ward 18) }\end{array}$ & 179 & 136 & 38 & 18 & 20 \\
\hline 4 & Kirakokhor (Rupakot, 8) & 280 & 92.25 & 56 & 29 & 27 \\
\hline 5 & $\begin{array}{l}\text { Furketari (Lekhnath Municipality, } \\
\text { Ward 29) }\end{array}$ & 48 & 15.69 & 27 & 15 & 12 \\
\hline 6 & Total & 913 & & 213 & 107 & 106 \\
\hline
\end{tabular}

\section{Field survey}

A randomisation process was carried to select the $\mathrm{HH}$ for survey in each CFUG. Of the total HHs in each CFUG, we carried out the survey in more than $20 \%$ of the total HHs. A total of $213 \mathrm{HHs}$ were surveyed in five CFUGs (Table 1) including 107 male and 106 female.

A self-administered, semi-structured survey instrument was developed and survey was carried out in selected households in September and October 2017. Questionnaires were given to the head of each household - the individual responsible for making most decisions on behalf of the family. The questions were related to collect information on respondent demographics, FUC member, access to CF fund, income sources, and distance from the market, migration and the women participation in different $C F$ decision making activities. Similarly, we observed women participation in different activities and analysed CFUGs documents, district forest office reports and available literatures minutely.

Participation of women in different decision making activities is the dependent variable in our statistical model, and is operationalised as the actual involvement in the following community forestry activities: (1) Forest management activities, (2) resource utilization activities, and (3) participatory activities (Fig. 2).

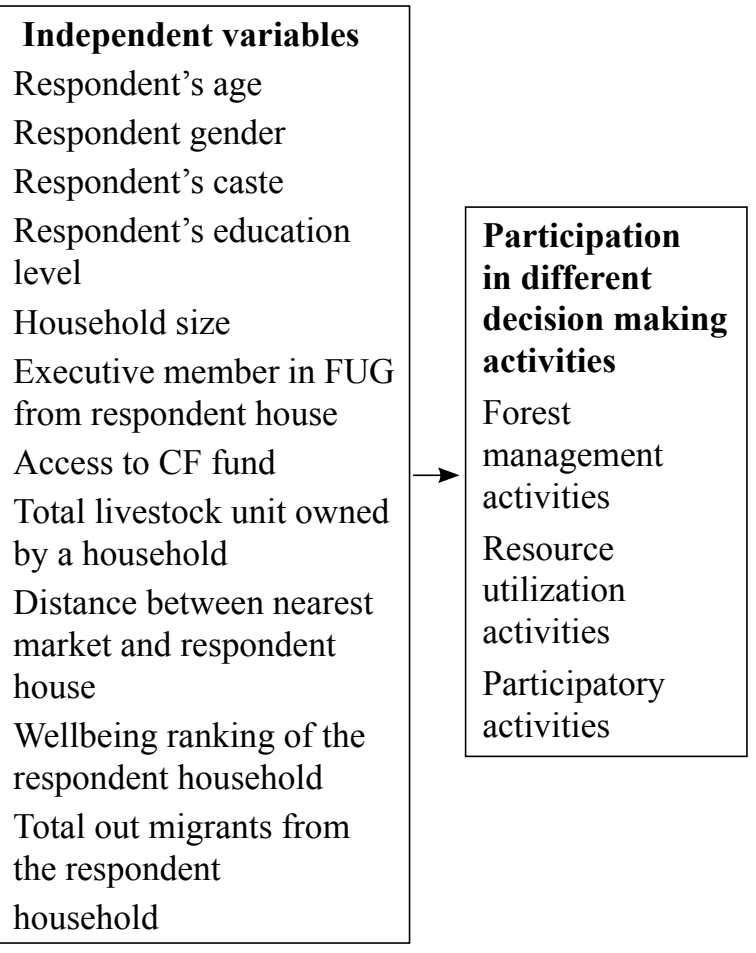

Fig. 2: Factors impacting women participation in community forestry decision making activities

Respondents were asked to rate their level of participation on a four-point scale ranging from 'no' participation to a 'high' level of participation. The independent variables represent the social, 
economic and biophysical conditions. Definitions and descriptions of the independent variables are presented in Table 2 .

Table 2: Definitions and descriptions of independent variables

\begin{tabular}{|l|l|c|}
\hline Variable name & \multicolumn{1}{|c|}{ Variable description } & $\begin{array}{c}\text { Variable } \\
\text { type* }\end{array}$ \\
\hline R_AGE & Respondent's age (year) & C \\
R_SEX & Respondent gender $(1=$ male $)$ & B \\
R_CASTE & Respondent's caste $(1=$ other than Dalits $)$ & B \\
R_EDU & Respondent's education level & C \\
HH_SIZE & Household size & C \\
FUC_M & Executive member in FUG from respondent's house $(1=$ yes $)$ & B \\
ACS_CF & Access to CF fund (1= yes) & B \\
TOTAL_LSU** & Total livestock unit owned by a household & C \\
DIS_MIN & Distance between nearest market and respondent's house & C \\
WEL_BE_D & Wellbeing ranking of the respondent household & C \\
OUT_MIG & Total out migrants from the respondent household & C \\
\hline
\end{tabular}

${ }^{*} \mathrm{C}=$ continuous $\quad \mathrm{B}=$ binary

**All livestock converted into livestock units (LSU) using the following formula: $1 \mathrm{LSU}=1$ buffalo $=$ 1.2 cows $=4$ goats $=5$ sheep $=4$ Pigs $=2$ calves (Otte and Chilonda, 2002) .

\section{Statistical analysis}

Descriptive statistics values were used to summarize and present the data. Different decision making activities were taken as average with three major divisions and level of participation in each activity calculated and analysed in terms of gender. Cross tabulations were also used to compare the frequency distribution of one variable to another. We used Pearson productmoment correlation coefficients to determine the magnitude and direction of the relationship between women participation in different decision making activities and continuous independent variables. Chi-square tests were used to examine the degree of association between participation and independent variables.

An econometric approach was used to analyse the participation in decision making activities in terms of gender in forest management, resource utilization, and participatory activities. The effect of different independent variables on levels of participation in decision making activities in forest management, resource utilization, and participatory activities were estimated using ordered logit regression models (Chhetri et al, 2013). An ordered logit model is preferable because our categorical dependent variable (participation in decision making activities) is neither continuous nor normally distributed. As demonstrated by the conceptual framework (Fig. 2 ), participation is described as a function of economic, social, and biophysical factors.

\section{Results and discussion}

Among the respondents, $75 \%$ had some education, $10 \%$ had higher education and $15 \%$ had no formal education. In terms of gender, higher percentage of women had primary and secondary education $(80 \%)$ and only $4 \%$ women had higher education. Also the male respondents were more in EC of the CFUG compared with the female members. People perceive position in EC in the CFUG as the symbol of high social status. Most of the committee members were from wealthy and elite groups. During the survey women were busy 
in farm and household activities whereas male members were found utilizing their leisure time playing cards and gossiping in tea shops.

The results are presented in table and figures. The descriptive statistics of independent variables are presented in Table 3. The role and access of women in different CFUG activities are shown in Figure 3. Different level of participation in decision making activities like forest management, resource utilization and participatory activities is presented in Table 4 . Similarly, Table 5 represents Community forestry decision making activities and participation level in per cent. The correlation coefficient between different continuous independent variables and chi-square of categorical variables are presented in Table 6 and Table 7, respectively. Finally the Table 8 presents the empirical results from ordered logit model analysis of participation in decision making activities in community forestry. In each of participation category the chi-square values were significant at less than 0.001 level, this suggests that the regression model has high level of explanatory power indicating that the independent variables have relation with the dependent variables.

The coefficients presented in Table 8 were used to interpret the direction of the change that each variable contributes to the model. Similarly, the p-values associated with the coefficient describe on how significantly each independent variable contributes to overall variation in the model. The cut points are the ancillary parameters on the standardised normal distribution for each point of the independent variable.

Table 3: Descriptive statistics for independent variables $(\mathrm{N}=\mathbf{2 1 3})$

\begin{tabular}{|l|c|c|c|c|}
\hline Variables & Minimum & Maximum & Mean & $\begin{array}{c}\text { Standard } \\
\text { Deviation }\end{array}$ \\
\hline R_AGE & 26 & 88 & 51.24 & 13.09 \\
\hline R_SEX & 0 & 1 & 0.50 & 0.50 \\
\hline R_CASTE & 0 & 1 & 0.87 & 0.33 \\
\hline R_EDU & 0 & 18 & 5.73 & 4.34 \\
\hline HH_SIZE & 1 & 15 & 5.87 & 2.51 \\
\hline FUC_M & 0 & 1 & 0.18 & 0.38 \\
\hline ACS_CF & 0 & 1 & 0.20 & 0.41 \\
\hline TOTAL_LSU & 0 & 12.67 & 2.09 & 1.78 \\
\hline DIS_MIN & 10 & 90 & 35.07 & 32.12 \\
\hline
\end{tabular}

\begin{tabular}{|l|c|c|c|c|}
\hline \multicolumn{1}{|c|}{ Variables } & Minimum & Maximum & Mean & $\begin{array}{c}\text { Standard } \\
\text { Deviation }\end{array}$ \\
\hline WEL_BE_D & 0 & 1 & 0.79 & 0.41 \\
\hline OUT_MIG & 0 & 3 & 0.38 & 0.59 \\
\hline
\end{tabular}

The women's access and role in CFUG resources was found inadequate (Fig. 3). Around $50 \%$ of the women respondents $(\mathrm{n}=106)$ stated that they had medium access in CFUG resources, which was followed by low access (38\%). Similarly, the role of women in monitoring activities was found insignificant. Based on almost half (49\%) of the respondents out of total respondents $(n=213)$, women had medium role in $\mathrm{CF}$ monitoring activities whereas $34 \%$ agreed that women had low role in monitoring activities. However, the role of women in implementation activities seemed comparatively better than that in monitoring and access to resources (Fig. 3). The major activities carried out by women in CFUGs were forest management activities like thinning, cleaning, pruning, plantation, fuel wood and fodder collection, etc. This implied that in key CF process like resources management and decision making activities women were largely kept aloof, whereas their participation seems comparatively higher during implementation activities which largely include regular forest management activities.

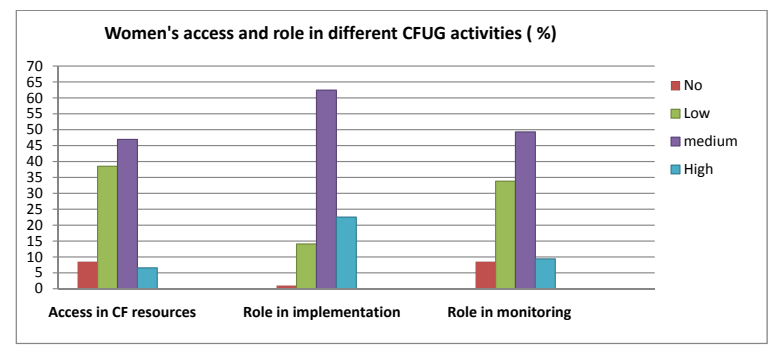

\section{Fig. 3: Women's access and role in CFUG activities in research sites}

On an average, respondents showed greater degree of participation in decision making in participatory activities followed by forest management and resource utilization activities. Compared with the men, the women participation was found low in all decision making activities. Moreover, majority of the women respondents had low or/and no participation in each activity. The women had high degree of participation in participatory activities followed by forest management and resource utilization activities 
and the same trend in level of participation was found in men (Table 4). The medium to high level of participation of men was

Table 4: Community forestry decision making activities and overall participation level $(\mathrm{n}=\mathbf{2 1 3})$

\begin{tabular}{|c|c|c|c|c|c|}
\hline \multicolumn{2}{|c|}{ Participation in CFUG decision making activities } & \multirow{2}{*}{$\begin{array}{r}\text { No } \\
7(3.3)\end{array}$} & \multirow{2}{*}{$\frac{\text { Low }}{37(17.4)}$} & \multirow{2}{*}{$\begin{array}{l}\text { medium } \\
45(21.1)\end{array}$} & \multirow{2}{*}{$\frac{\text { high }}{18(8.5)}$} \\
\hline $\begin{array}{l}\text { Forest management activities (protection } \\
\text { measures, silvicultural activities, product }\end{array}$ & Male & & & & \\
\hline $\begin{array}{l}\text { distribution, block division, OP implementation } \\
\text { and monitoring) }\end{array}$ & Female & $23(10.8)$ & $52(24.4)$ & $21(9.9)$ & $10(4.6)$ \\
\hline \multirow{2}{*}{$\begin{array}{l}\text { Resource utilization activities (resource } \\
\text { collection, price allocation of forest product, } \\
\text { fund allocation for different activities, fund } \\
\text { allocation for capacity development, IGA) }\end{array}$} & Male & $9(4.23)$ & $42(19.72)$ & $38(17.84)$ & $18(8.45)$ \\
\hline & Female & $29(13.62)$ & $50(23.47)$ & $20(9.39)$ & $7(3.3)$ \\
\hline \multirow{2}{*}{$\begin{array}{l}\text { Participatory activities (users identification, } \\
\text { FUC formation, Inclusion of women's concerns } \\
\text {, OP preparation, time setting to enter in the } \\
\text { forest for silvicultural and harvesting purpose) }\end{array}$} & Male & $7(3.3)$ & $31(14.55)$ & $50(23.47)$ & $19(8.92)$ \\
\hline & Female & $21(9.9)$ & $42(19.72)$ & 2913.62() & $14(6.57)$ \\
\hline
\end{tabular}

considerably higher in participatory activities than that of women (men $=64.5 \%$; women $=40.6 \%$ ) (Table 5). The men participation in decision making was found higher in all activities. The

Table 5: Community forestry decision making activities and participation level (\%) (n=107 for male and $n=106$ for female respondents)

\begin{tabular}{|c|c|c|c|c|c|}
\hline \multicolumn{2}{|l|}{ Participation in CFUG decision making activities } & No & Low & medium & high \\
\hline \multirow{2}{*}{$\begin{array}{l}\text { Forest management activities (protection measures, } \\
\text { silvicultural activities, product distribution, block } \\
\text { division, OP implementation and monitoring) }\end{array}$} & Male & 6.5 & 34.6 & 42.1 & 6.8 \\
\hline & Female & 21.7 & 49.1 & 19.8 & 9.4 \\
\hline \multirow{2}{*}{$\begin{array}{l}\text { Resource utilization activities (resource collection, } \\
\text { price allocation of forest product, fund allocation } \\
\text { for different activities, fund allocation for capacity } \\
\text { development, IGA) }\end{array}$} & Male & 8.14 & 39.25 & 35.51 & 16.82 \\
\hline & Female & 27.35 & 47.17 & 18.87 & 6.60 \\
\hline \multirow{2}{*}{$\begin{array}{l}\text { Participatory activities (users identification, FUC } \\
\text { formation, Inclusion of women's concerns, OP } \\
\text { preparation, time setting to enter in the forest for } \\
\text { silvicultural and harvesting purpose) }\end{array}$} & Male & 6.54 & 28.97 & 46.73 & 17.75 \\
\hline & Female & 19.63 & 39.25 & 27.35 & 13.08 \\
\hline
\end{tabular}

result supports the traditional view that the women participation in decision making is lower than that of men in CFs and men always dominate in decision making activities in community forestry. Chhetri et al. (2013) and Wagle et al. (2017) also argue that the participation of women in CFUGs decision making activities is lower and is usually passive participants.

Participation in all decision making activities showed significant association with the gender implying that decision making is crucial and most influential in community forestry development. The level of participation of men in all decision making activities in CFs was significantly different with women (Table 6) and this finding is supported by chi-square test also (Table 7) and the other studies (Chhetri et al., 2013; Nightingale, 2002. In reality women had fewer choices and access in CF decision making activities than that of men. The domestic works, social norms and perceptions limit abilities and opinions of women (Agrawal, 2001). It obviously will create less opportunity for them to participate in CF decision making activities. Similarly, there is stereotype thought that women cannot decide in a better way so that the authority should not be provided directly to them. 
Table 6: Correlations between independent variables and participation in forest management, resource utilization, and participatory activities $(\mathrm{N}=\mathbf{2 1 3})$

\begin{tabular}{|l|l|l|l|}
\hline \multirow{2}{*}{ Independent variables } & \multicolumn{3}{|c|}{ Correlation coefficient } \\
\cline { 2 - 4 } & Forest management & Resource utilization & Participatory activities \\
\hline R_AGE & 0.252 & 0.253 & 0.242 \\
\hline R_EDU & 0.188 & 0.125 & 0.151 \\
\hline HH_SIZE & 0.134 & 0.186 & 0.127 \\
\hline TOTAL_LSU & 0.080 & 0.077 & 0.110 \\
\hline DIS_MIN & $0.011^{*}$ & 0.054 & $0.034^{*}$ \\
\hline
\end{tabular}

*Significant at $5 \%$ level

Table 7: Chi-square value for the tests comparing independent variables and participation in decision making in forest management, resource utilization and participatory activities

\begin{tabular}{|l|l|l|l|l|l|l|}
\hline \multirow{2}{*}{$\begin{array}{c}\text { Independent } \\
\text { variables }\end{array}$} & \multicolumn{2}{c|}{ Forest management } & \multicolumn{2}{c|}{ Resource utilization } & \multicolumn{2}{c|}{ Participatory activities } \\
\cline { 2 - 7 } & Chi & p-value & Chi & p-value & Chi & p-value \\
\hline R_SEX & 30.82 & $0.000^{*}$ & 24.47 & $0.000^{*}$ & 24.99 & $0.000^{*}$ \\
\hline R_CASTE & 2.25 & 0.522 & 3.55 & 0.314 & 4.15 & 0.245 \\
\hline FUC_M & 19.18 & $0.000^{*}$ & 18.89 & $0.000^{*}$ & 21.31 & $0.000^{*}$ \\
\hline ACS_CF & 23.58 & $0.000^{*}$ & 18.04 & $0.000^{*}$ & 25.22 & $0.000^{*}$ \\
\hline WEL_BE_D & 3.07 & 0.380 & 2.83 & 0.419 & 0.47 & 0.924 \\
\hline OUT_MIG & 2.83 & 0.829 & 3.90 & 0.690 & 3.98 & 0.679 \\
\hline
\end{tabular}

*Significant at $5 \%$ level

Our results showed that the HHs, who was not in the forest user executive committee, participated less in all decision making activities. This can be attributed to the fact that EC most often do not reflect the social structure and community at large. The local leaders and elites tend to dominate the executive position and decision making processes. Several researchers have shown that the low participation of women in forest user committee and nearly absence of key positions have marginalized their role in CF decision making activities. Agrawal (2010) states that women involvement in executive committee, which is the decision making body, is crucial for better women participation in decision making. Similarly, the proportionate strength of women in EC can help women to raise their voice and strengthen the governance of the CGUGs effectively. Further this will increase women participation in CF meetings, general assemblies and other gatherings.

The access to CF fund was significantly different with participation in all decision making activities (Table 7). The members with more access to $\mathrm{CF}$ fund participate more in decision making activities than those with less excess to CF fund. Usually, women have weak access during vital decision making in CF including the economic activities and this will obviously push them back to participate in decision making activities in CFUGs.

The age and education of the people had significant relation with decision making in forest management activities, however, there was no significant differences of age and education with participating in resource utilization activities and participatory activities (Table 8). The people with higher age had more association with forest management decision making activities. Similarly, the people with no formal education was less likely to participate in decision making in forest management activities, however, there was no relation with decision making in resource utilization and participatory activities. Thus, the men with higher age from educated HHs, who were in FUC committee, had significant association with the $\mathrm{CF}$ decision making process. According to Agrawal (2009), the CFs with older members in EC, particularly the older women in $\mathrm{EC}$ were more effective in forest management and decision making. 
Table 8: Determinants of participation in decision making in forest management, resource utilization and participatory activities

\begin{tabular}{|l|c|c|c|c|c|c|c|c|c|}
\hline \multirow{2}{*}{ Variables } & \multicolumn{3}{|c|}{ Forest management } & \multicolumn{3}{c|}{ Resource utilization } & \multicolumn{3}{c|}{ Participatory activities } \\
\cline { 2 - 10 } & Coefficient & $\begin{array}{c}\text { SD } \\
\text { error }\end{array}$ & P value & Coefficient & $\begin{array}{c}\text { SD } \\
\text { error }\end{array}$ & P value & Coefficient & $\begin{array}{c}\text { SD } \\
\text { error }\end{array}$ & P value \\
\hline R_AGE & 0.32 & 0.13 & $0.018^{*}$ & 0.21 & 0.12 & 0.095 & 0.30 & 0.14 & $0.036^{*}$ \\
\hline R_SEX & 0.90 & 0.35 & $0.011^{*}$ & 0.94 & 0.32 & $0.004^{*}$ & 0.82 & 0.33 & $0.015^{*}$ \\
\hline $\begin{array}{l}\text { R CASTE } \\
\text { CAn_ED }\end{array}$ & -0.48 & 0.420 & 0.239 & -0.39 & 0.37 & 0.286 & -0.32 & 0.4 & 0.413 \\
\hline R_EDU & 0.08 & 0.04 & $0.047^{*}$ & 0.37 & 0.39 & 0.338 & 0.63 & 0.035 & 0.071 \\
\hline HH_SIZE & 0.02 & 0.06 & 0.680 & 0.78 & 0.61 & 0.197 & 0.022 & 0.06 & 0.725 \\
\hline FUC_M & 1.27 & 0.33 & $0.001^{*}$ & 1.32 & 0.37 & $0.000^{*}$ & 1.41 & 0.42 & $0.001^{*}$ \\
\hline STS_CF & 1.22 & 0.33 & $0.000^{*}$ & 0.96 & 0.34 & $0.005^{*}$ & 1.28 & 0.38 & $0.001^{*}$ \\
\hline $\begin{array}{l}\text { TOTAL_ } \\
\text { LSU }\end{array}$ & 0.10 & 0.08 & 0.201 & 0.08 & 0.90 & 0.358 & 0.14 & 0.08 & $0.050^{*}$ \\
\hline DIS_MIN & -0.00 & 0.004 & 0.915 & 0.001 & 0.004 & 0.718 & 0.001 & 0.005 & 0.810 \\
\hline $\begin{array}{l}\text { W E L } \\
\text { BE_D }\end{array}$ & -0.26 & 0.37 & 0.569 & 0.18 & 0.33 & 0.574 & -0.35 & 0.31 & 0.263 \\
\hline $\begin{array}{l}\text { O U T } \\
\text { MIG }\end{array}$ & 0.12 & 0.23 & 0.591 & 0.16 & 0.24 & 0.494 & 0.29 & 0.23 & 0.202 \\
\hline Cut 1 & 0.30 & 0.79 & & 0.67 & 0.69 & & 0.59 & 0.82 & \\
\hline Cut 2 & 2.81 & 0.81 & & 2.97 & 0.72 & & 2.34 & 0.84 & \\
\hline Cut 3 & 5.26 & 0.89 & & 5.43 & 0.79 & & 5.26 & 0.94 & \\
\hline
\end{tabular}

*Significant at $5 \%$

The caste and the HHs size revealed no connection with the decision making activities (Tables 6,7 and 8). The total livestock holding affected the participation in decision making in participatory activities. This is obvious that the decisions on harvesting time are decided during participatory activities. The households with more livestock were more inclined to community forest resources to meet their fodder need. The distance to market showed significant relation with participation in decision making in forest management and participatory activities (Table 6). However, the regression analysis showed no significant association of market distance

With participation. Similarly, the participation in CFUG decision making activities was not significantly different with the out migration (Table 8).

\section{Conclusion}

The user's participation in community forest decision making activities is interrelated with various socio economic and biophysical factors. The women participation was low in all decision making activities. Women were more likely to participate in participatory activities followed by resource utilization and forest management activities. The gender, user group committee member and access to CF fund showed significant relation to the level of participation in decision making while the caste, household size, out migration and market distance have no relation to the level of participation in decision making.

The study suggests that the participation of women in decision making has greater significance in community forest management; however, their effective participation has not been practiced in community forests. Despite the policy provision to include $50 \%$ women in EC and at least one position of chairman or secretary, the lower representation in user group committee, the symbolic representation system, social and traditional beliefs and perceptions, the preoccupied assumption that women cannot lead, 
have resulted in low participation of women in decision making processes and put question in their capacities and ideas. Thus there is need for collective efforts to encourage women, enhance their pro-activeness and level of participation in decision making to ensure equitable benefits for all users. Similarly, the collective and focused facilitation should be given and prepare them to include in key posts in forest user group committee to encourage participation of women in decision making.

The study adds the empirical evidences on current status and trends of women participation in decision making activities in CF practice in Nepal. It also helps to scratch on the knowledge that there has been no substantial change in women participation in decision making in $\mathrm{CF}$ from the last decades in ground despite having some innovative policy changes to include and ensure women presence in CFUGs decision making positions. Hence further research on what difference can be made by women's presence in decision making should be carried out with more intensive analysis using both qualitative and quantitative data.

\section{Acknowledgements}

We are thankful for the Science and Power in Participatory Forestry (SCIFOR) project funded by Danish Consultative Research Committee on Development (DANIDA) Research for financial support. We are also grateful to Division Forest Office Kaski, Community Forest User Groups for sharing information and Dhurba Bahadur Malla, Thakur Giri, Sami Shrestha and Bishnu Paudel for helping us in the field work.

\section{References}

Agarwal, B. 2009. Gender and forest conservation: The impact of women participation in community forestry governance. Ecological Economics 68 (8-9): 27852799.

Agarwal, B. 2010. Does women's proportional strength affect their participation? Governing local forests in south Asia. World Development 38 (1): 98-112.

Agarwal, B. 2002. The hidden side of group behaviour: a gender analysis of community forestry in south Asia. In Group Behaviour and Development: Is the Market Destroying Cooperation? (eds.) Heyer, J., Stewart, F. and Thorp, R. Oxford University Press, Oxford, United Kingdom, 185-208.

Agrawal, B. 2001. Participatory exclusion, community forestry and gender: An analysis for South Asia and a conceptual framework. World Development 29: 16231648.

Chhetri, B. B. K., Johnsen, F. H., Konoshima, M. and Yoshimoto, A. 2013. Community forestry in the hills of Nepal: Determinants of user participation in forest management. Forest Policy and Economics 30: 6-13 http:// dx.doi.org/10.1016/j.forpol.2013.01.010.

DoF. 2018. Database on Community Forests in Nepal. Department of Forests, Ministry of Forests and Soil Conservation, Kathmandu, Nepal.

Elias, M., Hummel, S. S., Basnett, B. S. and Colfer, C. J. P. 2017. Gender bias affects forests worldwide. Ethnobiology Letter 8 (1): 3134, DOI 10.14237/ebl.8.1.2017.834

FAO and RECOFTC.2015. Understanding Women's Participation in Forestry in Nepal. Policy Brief. Bangkok, Thailand.

Howard, P. L. and Nabanoga, G. 2007. Are there customary rights to plants? An inquiry among the Baganda (Uganda), with special attention to gender. World Development 35 (9): 1542-1563.

Kumar, N. 2002. The Challenges of Community Participation in Forest Development in Nepal. Operations Evaluation Department Working Paper No. 27931. The World Bank. Washington, D.C, USA.

Lama, A. S., Kharel, S. and Ghale, T. 2017. When the men are away: migration and women's participation in Nepal's community forestry. Mountain Research and Development 37 (3): 263-270.

MFSC. 2012. Forest Sector Gender and Social 
Inclusion Strategy. Ministry of Forests and Soil Conservation, Singhadurbar, Kathmandu, Nepal.

Nightingale A. J. 2002. Participating or just sitting in? The dynamics of gender and caste in community forestry. Journal of Forest and Livelihood 2 (1):17-24.

Ojha, H. and B. Pokharel. 2005. Democratic innovations in community forestry-What can politicians learn? Participation 7 (7): $22-25$.

Otte, M. and Chilonda, P. 2002. Cattle and Ruminant Production Systems in Subsaharan Africa. A Systematic Review. Food and Agriculture Organisation, $\mathrm{ftp} / / / \mathrm{ftp}$.fao.org/docrep/fao/005y4176E/ y4176E00.pdf.

Pokharel, B. K., Branney, P., Nurse, M. and Malla, Y. B. 2007. Community forestry: Conserving forests, sustaining livelihoods and strengthening democracy. Journal of Forest and Livelihood 6: 8-19.

Shiva, V., 1989. Staying Alive: Women, Ecology and Development. Zed Books, London, UK.

Wagle, R., Oli, D., Sapkota, B., Aryal, S. and Prajapati, S.M., 2017. Feminist institutionalist interpretation of forest tenure regimes in Nepal. Journal of Forest and Livelihood 15 (1): 131-142. 